\title{
Perfil de Metilación de Genes Supresores de Tumores APAF1, ASSP1, p73 y FHIT en Pacientes con Leucemia Linfoblástica Aguda Infantil
}

\author{
Detection of Hypermethylation in Tumor Suppressor Genes APAF1, \\ ASSP1, p73 and FHIT in Childhood Acute Lymphoblastic Leukemia
}

\begin{abstract}
Angélica Melo A."; Carmen Gloria Artigas A.**; Sergio Muñoz N.***;
\end{abstract} Priscilla Brebi M.*; Rene Hoffstetter G." \& Juan Carlos Roa S.",

MElO, A. A.; ARTigas, A. C. G.; MUÑOZ, N. S.; BREBI, M. P.; HOFFSTETTER, G. R. \& ROA, S. J. C. Perfil de Metilación de genes supresores de tumores APAF1, ASSP1, p73 y FHIT en pacientes con leucemia linfoblástica aguda infantil. Int. J. Morphol., 31(3):973-979, 2013.

RESUMEN: La leucemia linfoblástica aguda (LLA), es la neoplasia mas frecuente en la población infantil. Se manifiesta por una perdida de diferenciación de progenitores linfoides produciendo un aumento de células inmaduras. La hipermetilación en la región promotora de genes supresores de tumores (GST) puede producir un silenciamiento génico que le proporciona a la célula leucémica una ventaja proliferativa o la previene de la apoptosis. Se estudia el estado de hipermetilación de 4 GST involucrados en la apoptosis: APAF1, ASPP1, p73 y FHIT y su asociación con la sobrevida de pacientes menores de 15 años con diagnóstico de LLA. Se analizaron 38 muestras de médula ósea mediante modificación con bisulfito del ADN y reacción en cadena de la polimerasa especifica de metilación (MSP). El rango de edad al diagnóstico fue de 10 meses a 13,8 años. La sobrevida global fue de 69\% a los 5 años. El 81,5\% de los pacientes tuvo al menos un gen hipermetilado. La frecuencia de metilación observada fue: APAF1 68,4\%, FHIT 56,4\%, p73 42\% y ASPP1 18,4\%. La asociación entre hipermetilación y grupo $<5$ años y $\geq 5$ años fue: Global p=0,20, APAF1 p=0,03, FHIT p=0,51, p73 $\mathrm{p}=0,51$ y ASPP1 $\mathrm{p}=0.67$. Las curvas de sobrevida se calcularon según frecuencia de hipermetilación de cada gen: APAF1 p=0,05, FHIT $\mathrm{p}=0,31, \mathrm{p} 73$ p=0,98 y ASPP1 p=0,82. La alta frecuencia de hipermetilación obtenida reafirma la participación de la metilación en la región promotora de GST en la patogénesis de la LLA. La hipermetilación del gen APAF1 fue muy frecuente y se asoció significativamente a la sobrevida del grupo de estudio, mostrando a este gen como un factor predictivo de mal pronostico en pacientes con LLA.

PALABRAS CLAVE: Hipermetilación; Leucemia linfoblástica aguda Infantil; Genes supresores de tumores; Genes blanco de p53; Apoptosis; Sobrevida.

\section{INTRODUCCIÓN}

En Chile existe poca información sobre estudios moleculares en Leucemias (Artigas et al., 2002, 2003, 2006; Reyes et al., 2011). Esta neoplasia es la más frecuente en niños menores de 15 años, correspondiendo al 35-40\% del total de cánceres en la población infantil. La leucemia linfoblástica aguda (LLA) es el tipo de Leucemia mas frecuente con un $80 \%$ de los casos. Se ha descrito una incidencia anual de 2,5 a 3 casos por cada 100.000 niños menores a 15 años lo que equivale entre 100 y 110 nuevos casos cada año (Guía Clínica Leucemia menores de 15 años Minsal el
2010). La LLA, es un trastorno maligno que se origina en una célula hematopoyética única progenitora de linfocitos $\mathrm{B}$ o T y se caracteriza por una pérdida de diferenciación de progenitores linfoides produciendo un aumento en células linfoblásticas inmaduras (Pui et al., 2008). La hipótesis mas aceptada es que interactúan en la leucemogénesis múltiples factores, genéticos, epigenéticos y ambientales. La hipermetilación de sitios $\mathrm{CpG}$ en la región promotora de genes supresores de tumores (GST) es un evento epigenético adquirido, frecuente en la LLA y contribuiría en el proceso

Laboratorio de Patología Molecular, Facultad de Medicina, BIOREN-CEGIN, Universidad de La Frontera, Temuco, Chile.

** Tecnología Médica. Facultad de Ciencias de la Salud. Universidad San Sebastian Santiago, Chile

**** Departamento de Salud Pública. Capacitación Investigación y Gestión en Salud (CIGES). Facultad de Medicina. Universidad de La Frontera. Temuco, Chile.

***** Departamento Patología. Facultad de Medicina. Pontificia Universidad Católica de Chile, Santiago, Chile.

Financiamiento: Esta investigación fue financiada por el Proyecto CORFO N²12IDL2-18157, Proyecto DIUFRO 09-0028, Proyecto CORFO-CEGIN $\mathrm{N}^{\circ} 09 \mathrm{CN} 14-5960$, Scientific and Technological Bioresource Nucleus (BIOREN); Proyecto FONDECYT Postdoctoral N 3120141 (P. Brebi). 
de patogénesis. Por tanto, la inactivación de uno o más GST, participes en diferentes vías metabólicas, le proporcionan a la célula leucémica una ventaja proliferativa o impiden el proceso de apoptosis celular (Melki \& Clark, 2002; Galm et al., 2006; Pui et al.).

En tumores con p53 normal se ha observado que este gen no suprime el crecimiento tumoral ni desencadena la apoptosis. Este hecho, ha llevado a pensar que otros genes estarían provocando alteraciones en la vía de p53 (Agirre $e t$ al., 2003; Vilas-Zornoza et al., 2011). Este estudio se focalizó en cuatro GST que participan en la vía de apoptosis. El gen APAF1 (apoptotic peptidase activating factor 1) juega un rol importante en la inducción de la apoptosis. Se ha reportado que la hipermetilación es un mecanismo de inactivación de este gen en la leucemia aguda y su deficiencia puede contribuir de modo significativo sobre la resistencia a la apoptosis, la progresión de la enfermedad y en la quimioresistencia (Furukawa et al., 2005; Jia et al., 2001). El gen ASPP1 (apoptosis-stimulating protein of p53, 1) perteneciente a la familia de proteínas ASPP (ASPP1, ASPP2, iASPP) han sido implicadas en la función apoptótica de p53 y de la familia del p53 (p63 y p73) (Bergamaschi et al., 2004). ASPP1 y ASPP2 actúan como potentes activadores de p53 e iASPP como un inhibidor de la función apoptótica de p53 (Liu et al., 2005). La expresión protéica de ASSP1 se ha observado que se encuentra reducida en la LLA, atribuyendo esto a la hipermetilación del promotor. Además, la expresión anormal de ASPP1 se ha asociado con un pobre pronóstico en la LLA (Agirre et al., 2006). El gen p73 está involucrado en la regulación del ciclo, apoptosis y progresión celular. La hipermetilación y subsecuente inactivación del gen ha sido descrita como un hallazgo común en desordenes linfoproliferativos malignos, LLA y linfoma no Hodgkin (Pluta et al., 2006; Corn et al., 1999). El gen FHIT (Fragile Histidine Triad) participa en la regulación de la apoptosis y en el ciclo celular. Se ha descrito la hipermetilación de este gen en LLA infantil y del adulto. Una frecuente pérdida de su expresión en las LLA, sugiere que los eventos que lo inactivan contribuyen al desarrollo de la leucemia (Zheng et al., 2004; Román-Gómez et al., 2005).
En este estudio nos propusimos como objetivo evaluar el estado de metilación de los genes GST: APAF1, ASPP1, p73 y FHIT mediante MSP en muestras de pacientes menores a 15 años con diagnostico de LLA, para conocer la frecuencia y asociación entre el patrón de hipermetilación y la sobrevida del paciente.

\section{MATERIAL Y MÉTODO}

Muestras.Se estudiaron 38 muestras de médula ósea (MO) de pacientes no tratados, con diagnóstico de LLA, provenientes de Oncopediatría del Hospital Hernán Henríquez Aravena, Temuco, Chile, cuyas muestras fueron enviadas, para estudio de translocaciones cromosómicas, al Laboratorio de Patología Molecular de la Facultad de Medicina de la Universidad de La Frontera de Temuco, entre los años 1999-2007. Todos los pacientes contaban con consentimiento informado aprobado por el Comité de Ética del Servicio de Salud Araucanía Sur. Se realizó un seguimiento hasta marzo de 2013. En este estudio no contamos con controles normales debido al tipo de muestras utilizadas.

Extracción del ADN. Se realizó con el kit Puregene (Gentra, USA) para extracción de ADN genómico, siguiendo las instrucciones del fabricante. Brevemente, una alícuota de MO se trató con buffer para lisar glóbulos rojos, posteriormente al concentrado de leucocitos se agregó buffer de lisis. El ADN se precipitó con isopropanol, se hidrató y se almacenó a $-70^{\circ} \mathrm{C}$ hasta su análisis. Previo a la modificación, el ADN fue cuantificado en un espectrofotómetro ND-1000 (Nanodrop). Posteriormente, se amplificó un fragmento de $268 \mathrm{pb}$ del gen de la B-Globina utilizando los iniciadores PCO4 5' CAACTTCATCCACGTTCACC 3' y GH20 5' GAAGAGCCAAGGACA GGTAC 3', para asegurar la calidad del ADN y descartar muestras con ADN no amplificable.

Modificación del ADN con Bisulfito de sodio. Esta reacción química se fundamenta en la capacidad del bisulfito de sodio de convertir mediante deaminación, todas las citosina

Tabla I. Secuencias de los iniciadores para PCR Metilación específica y tamaño de los fragmentos amplificados.

\begin{tabular}{lllcc}
\hline Genes & $\begin{array}{l}\text { Iniciador forward } \\
\text { Secuencia 5'-3' }\end{array}$ & $\begin{array}{l}\text { Iniciador Reverse } \\
\text { Secuencia 5'-3' }\end{array}$ & $\begin{array}{c}\text { Fragmento } \\
\text { (pb) }\end{array}$ & $\begin{array}{c}\text { Referencias } \\
\text { Bibliográfica }\end{array}$ \\
\hline APAF1 & TTTCGGGTAAAAGGGATAGAATTAGA & TATAACGCCCTTCCCCCGACGACG & 140 & Fu et al. (2003) \\
ASPP1 & AAGTAGGTGTTAGTTAAGGGCGTC & ACCGACTATAAACCGAAAACGT & 205 & Agirre et al. (2006) \\
p73 & GGACGTAGCGAAATCGGGGTTC & ACCCCGAACATCGACGTCCG & 60 & Corn et al. (1999) \\
FHIT & TTGGGGCGCGGGTTTGGGTTTTTACGC & CGTAAACGACGCCGACCCCACTA & 75 & Zheng et al. (2004) \\
\hline
\end{tabular}


no metiladas en uracilos, mientras que aquellas citosinas metiladas (5metilcitosinas) resisten la modificación y permanecen como citosinas (Hermann et al., 1996). 2-4 $\mu \mathrm{g}$ de ADN fueron denaturados con $\mathrm{NaOH}$, se agrego bisulfito de sodio $4,2 \mathrm{M} \mathrm{pH} 5$ y se incubó a $50^{\circ} \mathrm{C}$ durante 16 horas. El ADN fue purificado y concentrado mediante tubos Centricon YM 30 (Millipore, Bedford, MA). Se hidrato en agua estéril y se procesó dentro de los 15 días siguientes a la modificación.

PCR gen específica para Metilación (MSP) . Está diseñada para distinguir ADN metilado del no-metilado con iniciadores que reconocen el cambio en la secuencia, post-modificación del ADN con bisulfito. Esta técnica es muy sensible ya que detecta $0,1 \%$ de ADN metilado, haciendo posible detectar alelos metilados en una muestra con baja población de células neoplásicas (Hermann et al.).

Se utilizaron sólo los iniciadores que detectan secuencias metiladas, debido a que la muestras de medula ósea contenían una mezcla de células normales y neoplásicas. Para la MSP de los genes APAF1, ASPP1, p73 y FHIT, se emplearon las secuencias de iniciadores que han sido previamente publicadas (Tabla I).

Programa de la MSP. La reacción se efectuó en $100 \mu \mathrm{g}$ de ADN genómico modificado, $0,5 \mu \mathrm{M}$ de iniciadores, $0,04 \mathrm{U} / \mu 1$ de Taq polimerasa (Applied Biosystems). Se usaron 35 ciclos y una temperatura de hibridación de $60^{\circ} \mathrm{C}$.

Controles. Se usó como control negativo ADN modificado no metilado, como control blanco ADN sin modificar sin metilar y como control positivo de metilación, ADN genómico comercial (Promega) previamente metilado con la enzima ADN metiltransferasa (New England Biolab, MA) y modificado con bisulfito de sodio.

Análisis estadístico. Se confeccionaron tablas de contingencia para cada uno de los genes y se calculó la frecuencia de metilación. Se calcularon

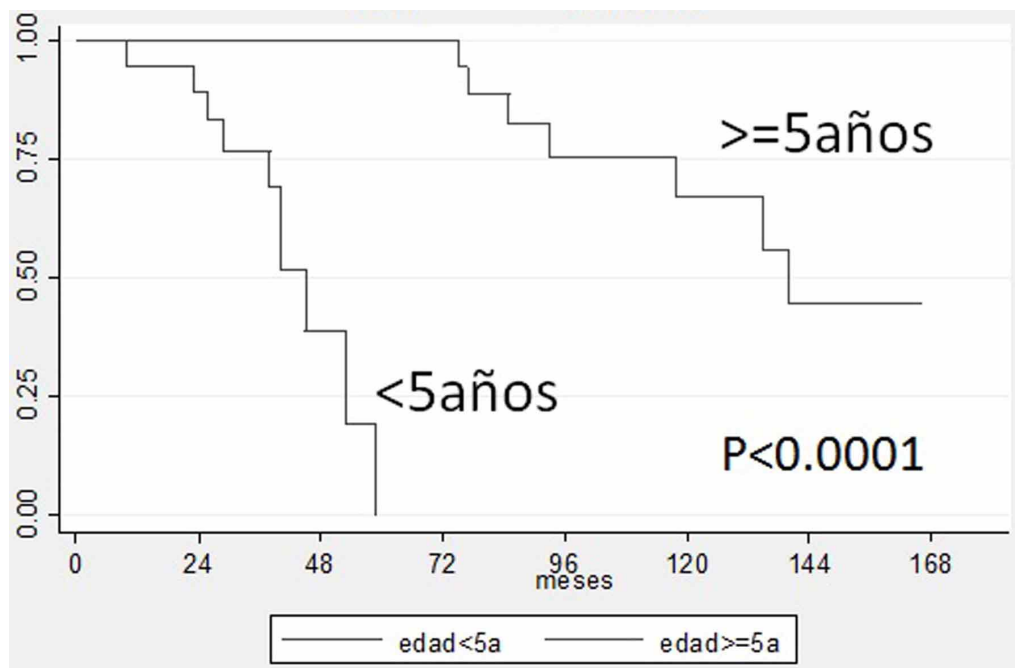

Fig. 1. Sobrevida de los pacientes (curva de Kaplan-Meier) según la edad al diagnóstico. las curvas de sobrevida de Kaplan-Meir, comparando el tiempo de sobrevida entre los pacientes que tenían genes metilados y no metilados aplicando la prueba de logRank.

\section{RESULTADOS}

El grupo de estudio estuvo compuesto de 17 hombres $(47,4 \%)$ y 21 mujeres $(55,3 \%)$, menores de 15 años, con un rango de edad al diagnostico de 10 meses a 13,8 años. La sobrevida global fue de $69 \%$ a los 5 años y $46 \%$ a 10 años. Al comparar la sobrevida según la edad el resultado fue altamente significativo ( $\mathrm{p}=0,0001)$ recayendo la mayoría de las muertes en el grupo <5años (10/17) (Fig. 1).

En la Figura 2 se muestran fotos de las MSP y de la PCR para la b-globina. Para el análisis de los resultados se considero el total de pacientes y además se dividió el grupo de estudio por edad al momento del diagnostico en $<5$ años $\mathrm{y} \geq 5$ años.

Hipermetilación del set de GST. El 81,5\% del total de pacientes tuvo al menos un gen hipermetilado y en el $18,4 \%$ no se detectaron genes hipermetilados. La frecuencia de hipermetilación específica según cada gen fue: APAF1 68,4\%, FHIT 56,4\%, p73 42\% y ASPP1 18,4\% (Tabla II).

Hipermetilación según edad. La frecuencia con al menos un gen hipermetilado fue de $73,7 \%$ para el grupo < 5años y de $89,5 \%$ en $\geq 5$ años $(\mathrm{p}=0,202)$. Cuando se relacionó la edad y la hipermetilación gen específico se observo significancia estadística en el gen APAF ( $p<0.05)$, en los genes FHIT, p73 y ASPP no se obtuvo un p significativo $(0,676$, 0,511 y 0,511 respectivamente).

Hipermetilación según estado vital. En la Figura 3 se muestra el estado vital del paciente y la presencia de hipermetilación. Destaca que el número de pacientes fallecidos es mayor a los casos vivos cuando tienen cero, 3 y 4 genes hipermetilados.

Curvas de sobrevida. Se calcularon de acuerdo al perfil de hipermetilación de cada gen, 


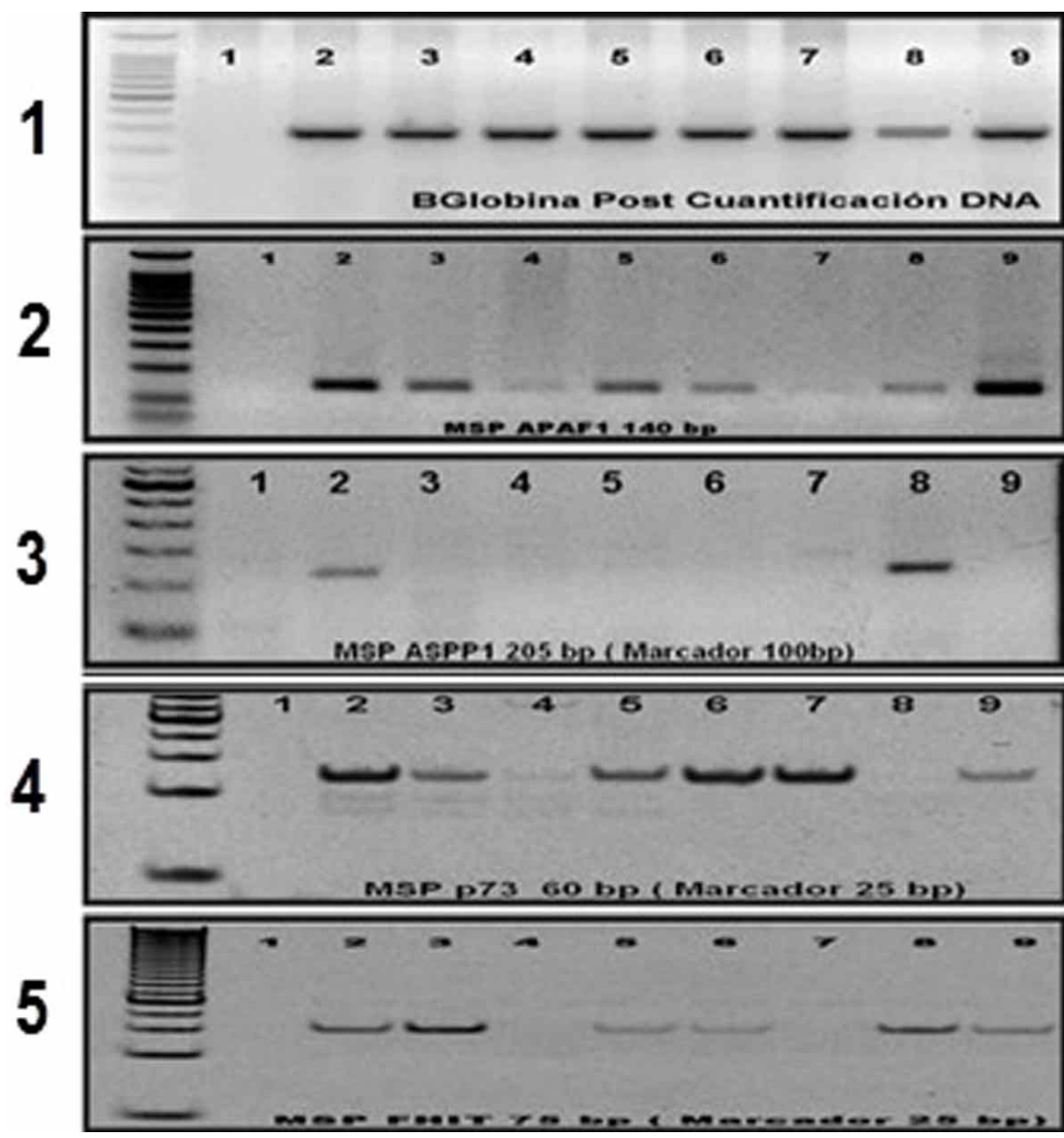

Fig. 2. PCR gen B-Globina (1). MSP: gen $\operatorname{APAF}(2)$ gen $\operatorname{ASPP}(3)$, gen P73(4), gen FHIT(5). Marcador DNA 100 y 25bp. Carril 1: control blanco. Carril 2: control positivo DNA genómico 1/100 (1) y DNA metilado (2, 3,4 y 5). Carril 3 al 9 muestras de LLA. Los productos PCR fueron visualizados en geles de agarosa al $2 \%$, Poliacrilamida al 12\% (FHIT y p73) y teñidos con bromuro de etidio. cuyo análisis estadístico mostró: APAF1 p=0,05, FHIT p=0,31, p73 $\mathrm{p}=0,98$ y ASPP1 $\mathrm{p}=0,82$ (Figura 4).

Índice de metilación. Se calculó dividiendo los genes hipermetilados por el total de genes en estudio. Solo 3 pacientes presentaron un $100 \%$ de los genes hipermetilados. Nueve casos presentaron 3/4 genes, 13 casos 2/4 y 6 casos 1/4. En la Figura 5 se muestra el índice de metilación según la edad de los pacientes al diagnostico $(\mathrm{p}=0,125)$. Se destaca que en el grupo de $\geq 5$ años el $47 \%$ tenía 2 genes hipermetilados.

Genes de Fusión. De los antecedentes clínicos revisados, 3/38 pacientes presentaban el gen de fusión BCR/ABL y 4/32 el TEL/AML1 positivo ( 6 casos no tenían realizado este examen).

Tabla II. Frecuencia de hipermetilación génica según edad del grupo de estudio

\begin{tabular}{lcccccc}
\hline & \multicolumn{6}{c}{ Hipermetilación génica (\%) } \\
\cline { 2 - 7 } Edad & $\mathbf{n}$ & APAF1 & ASPP1 & p73 & FHIT & Global \\
\hline$<5$ años & 19 & $10(38,5)$ & $3(42,5)$ & $7(43,7)$ & $10(45,5)$ & $14 / 19(73,7)$ \\
$>=5$ años & 19 & $16(61,5)$ & $4(57,1)$ & $9(56,2)$ & $12(54,5)$ & $17 / 19(89,5)$ \\
Total & 38 & $26(68,4)$ & $7(18,4)$ & $16(42,1)$ & $22(57,9)$ & $31 / 38(81,5 \%)$ \\
& & $\mathrm{p}<0,05$ & NS & NS & NS & NS \\
\hline
\end{tabular}

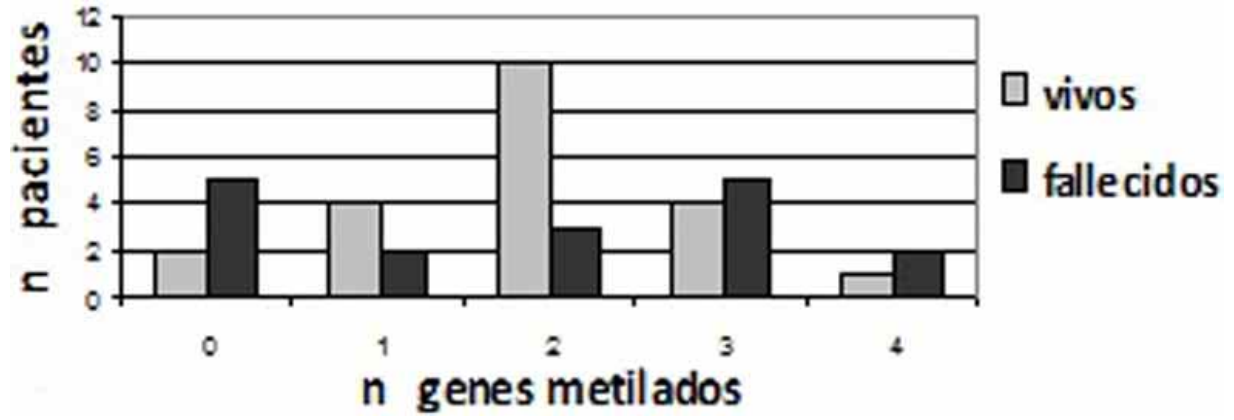

Fig. 3. Estado vital de los pacientes según genes metilados 




Fig. 4. Curva de sobrevida para el estado de metilación del gen APAF ( $\mathrm{p}=0,05)$.

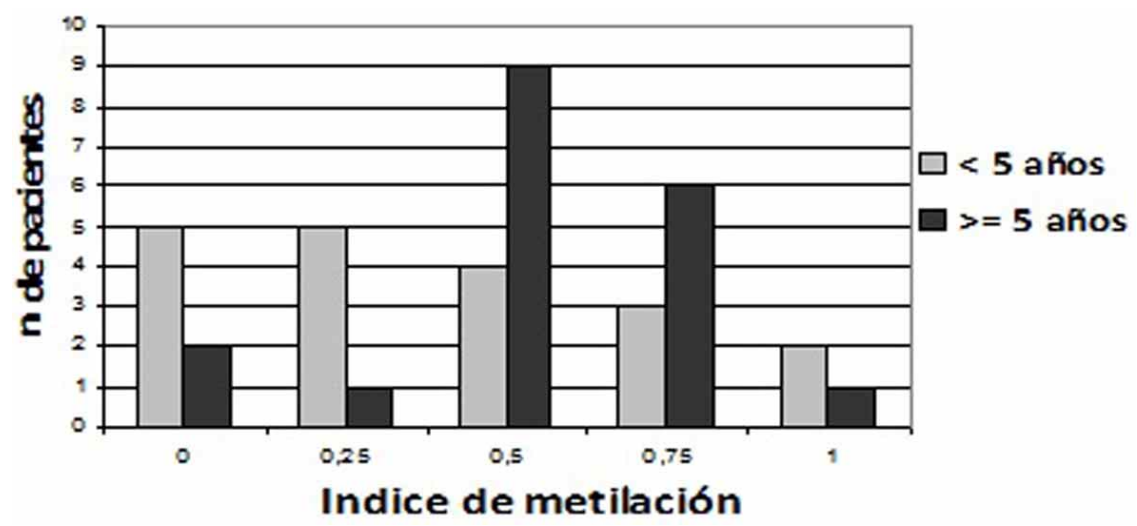

Fig. 5. Índice de Metilación según grupo de edad. Índice metilación (IM) n genes metilados/ genes analizados, $0=$ ningún gen metilado, $0,25=1$ gen, $0,5=2$ genes, $0,75=3$ genes y 1 $=4$ genes .

\section{DISCUSIÓN}

La LLA se presenta tanto en adultos como niños, siendo mucho mas frecuente en $<5$ años. La incidencia para edades específicas se reporta con un alza entre 2 y 5 años para descender durante la infancia tardía, adolescencia y adultez temprana (Piu, 2005). En los casos analizados predomina la edad de presentación entre los 2-3 años con un 38,9\%, lo que concuerda con lo mencionado para esta enfermedad. La distribución por sexo muestra un porcentaje menor de niños que la descrita en la literatura (Piu et al.). Este hecho puede deberse al azar, al n pequeño o la localización geográfica. La sobrevida global de los pacientes en estudio esta dentro del rango descrito para la población infantil chilena (Campbell, 2005).

Las frecuencias globales para los casos sin genes hipermetilados $(18,4 \%)$ y para al menos un gen hipermetilado $(81,5 \%)$ son similares a las reportadas en el estudio de Vilas-Zornoza et al., quines incluyen 3 de los 4 genes incluidos en el presente estudio.

Las frecuencias de hipermetilación para los genes FHIT y ASPP1 concuerdan con reportes previos (Stam RW et al., Agirre et al., 2006). Sin embargo, para los genes APAF1 y p73 las frecuencias de metilación fueron mas altas que las publicadas para LLA infantil (Canalli et al., 2005; Vilas-Zornoza et al.; Román-Gómez et al., 2004, 2005). Estas diferencias en los porcentajes podría darse, por la heterogeneidad en relación al subtipo de la LLA, factores étnicos, ambientales o geográficos, que podrían estar jugando un rol importante en las frecuencias de hipermetilación de los pacientes sometidos a estudio. Además, el número de casos incorporados en los estudio, también puede provocar una gran variabilidad en las frecuencias. Por ejemplo, esto se evidencia en los estudios de Yang et al. (2006), y Stam et al. (2006), que reportan un porcentaje de metilación para el gen FHIT de $20 \%(2 / 10)$ y $56 \%$ (24/43).

En relación a los casos que no presentaron genes hipermetilados y fallecieron, las causas pueden ser debidas a condiciones clínicas adicionales a la LLA u otras alteraciones moleculares o cromosómicas no contempladas en el presente estudio. Este hecho puede verse reflejado, cuando se asoció el número de genes y la sobrevida, en el cual se observó una mayor proporción de muertes en los pacientes con 2 o más genes hipermetilados sin embargo la muerte ocurre lejos en el tiempo, comparado con las muertes de los pacientes con uno o ningún gen hipermetilado que tuvieron una sobrevida más corta (datos no mostrados).

En el análisis de las curvas de sobrevida se obtuvo un resultado estadísticamente significativo para el 
gen APAF1 $(\mathrm{p}=0,05)$. Indicando que los pacientes que presentaron hipermetilación del gen APAF1 tuvieron una menor sobrevida. Este hecho concuerda con lo reportado para el gen APAF1 en relación a que sería un gen crítico en la vía de la apoptosis y su inactivación influye significativamente en el curso de la enfermedad (Furukawa et al.; Jia et al.).

De los 4 GST estudiados solamente el gen Apaf1 presento una asociación significativa $(\mathrm{p}<0,05)$ en relación al estado de hipermetilación y la edad. Cuando se consideró solo un gen hipermetilado según grupo de edad se obtuvo una frecuencia de hipermetilación de 73,7\% en $<5$ años versus $89,5 \%$ en los $\geq 5$ años ( $\mathrm{p}=0,202)$. Aunque no fue significativa la diferencia, se puede deducir, que a medida que la enfermedad se diagnóstica en pacientes con mayor edad, se observaría una mayor frecuencia de hipermetilación en los GST analizados. Estudios previos, han observado diferencias al comparar grupo de niños con adultos en distintas series de genes (Yang et al.; Vilas-Zornoza et al.).

De los 3 pacientes que presentaban el gen BCR/ABL, dos pacientes fallecieron. En ambos casos se detectó genes hipermetilados (4 y 2 genes). El 3er paciente no presentó genes hipermetilados y permanece vivo. Aunque son pocos casos, este hecho concuerda con lo sugerido por RománGómez et al., quienes mencionan que la ausencia de metilación ayudaría a mejorar el pronóstico de pacientes con LLA BCR/ABL positivo (Román-Gómez et al., 2004).

Uno de los 4 pacientes TEL/ALM1 (+) presentó los 4 genes hipermetilados y tuvo una sobrevida de 19 meses. En relación a este caso, se puede mencionar que el tener los 4 genes hipermetilados influyó en la sobrevida de este paciente, puesto que el gen TEL/AML1 se ha mencionado como un factor de buen pronóstico (Artigas et al., 2006). Hecho que se observa en los otros 3 pacientes que permanecen vivos con 59, 92 y 157 meses de sobrevida.

En conclución, la hipermetilacion del gen APAF1 fue muy frecuente y se asoció significativamente a la sobrevida del grupo de estudio, mostrando a este gen como un factor predictivo de mal pronóstico en pacientes con LLA. Por otro lado, la alta frecuencia de hipermetilación del set de GST reafirma la participación de la metilación en la región promotora de GST en la patogénesis de la LLA y hace necesario realizar una investigación adicional para buscar el grupo de GST más representativo, con el fin de complementar la detección de translocaciones génicas y ayudar en la clasificación molecular de las leucemias.

MELO, A. A.; ARTIGAS, A. C. G.; MUÑOZ, N. S.; BREBI, M. P.; HOFFSTETTER, G. R. \& ROA, S. J. C. Detection of hypermethylation in tumor suppressor genes APAF1, ASSP1, p73 and FHIT in childhood acute lymphoblastic leukemia. Int. J. Morphol., 31(3):973-979, 2013.

SUMMARY: Acute lymphoblastic leukemia (ALL) is the most common malignancy in children. It is manifested by a loss of differentiation of lymphoid progenitors, producing an increase of immature cells. Hypermethylation in promoter region of tumor suppressor genes (GST) may produce a gene silencing that provides a leukemic cell a proliferative advantage or prevent apoptosis. We studied the hypermethylation status of 4 GST involved in apoptosis: APAF1, ASPP1, p73 and FHIT and its association with survival of patients <15 years diagnosed with ALL. We analyzed 38 samples of bone marrow by DNA bisulfite modification and chain reaction methylationspecific polymerase (MSP). The mean age at diagnosis was 10 months to 13.8 years. Overall survival was $69 \%$ at 5 years. $81.5 \%$ of patients had at least one hypermethylated gene. The frequency observed was: APAF1 68.4\%, 56.4\% FHIT, p73 ASPP1 42\% and 18.4\%. The association between hypermethylation and group $<5$ years and $\geq 5$ years was: Global $p=0.20$, APAF1 $p=0.03$, FHIT $p=0.51, p 73$ $\mathrm{p}=0.51$, ASPP1 $\mathrm{p}=0.67$. Survival curves were calculated by frequency of hypermethylation of each gene: APAF1 $\mathrm{p}=0.05, \mathrm{p}=0.31$ FHIT, p73 p $=0.98$ and ASPP1 $p=0.82$. The high frequency of hypermethylation obtained confirms enrollment of methylation in the promoter region of GST in the pathogenesis of ALL. APAF1 gene hypermethylation was very frequent and was significantly associated with survival in the study group, showing this gene as a predictor of poor prognosis in patients with ALL.

KEY WORDS: Hypermethylation; Childhood acute lymphoblastic leukemia; Tumor suppressor genes; p53 target genes; Apoptosis; Survival.

\section{REFERENCIAS BIBLIOGRÁFICAS}

Agirre, X.; Novo, F. J.; Calasanz, M. J.; Larrayoz, M. J.; Lahortiga, I.; Valganon, M.; Garcia-Delgado, M. \& Vizmanos, J. L. TP53 is frequently altered by methylation, mutation, and/or deletion in acute lymphoblastic leukaemia. Mol. Carcinog., 38(4):201-8, 2003.
Agirre, X.; Roman-Gomez, J.; Jimenez-Velasco, A.; Garate, L.; MontielDuarte, C.; Navarro, G.; Vazquez, I.; Zalacain, M.; Calasanz, M. J.; Heiniger, A.; Torres, A.; Minna, J. D. \& Prosper, F. ASPP1, a common activator of TP53, is inactivated by aberrant methylation of its promoter in acute lymphoblastic leukemia. Oncogene, 25(13):1862-70, 2006. 
MELO, A. A.; ARTIGAS, A. C. G.; MUÑOZ, N. S.; BREBI, M. P.; HOFFSTETTER, G. R. \& ROA, S. J. C. Perfil de Metilación de genes supresores de tumores APAF1, ASSP1, p73 y FHIT en pacientes con leucemia linfoblástica aguda infantil. Int. J. Morphol., 31(3):973-979, 2013.

Artigas, C. G.; Cabrera, M. E.; Melo, A.; Páez, E.; Arriagada, M.; Astete, C.; Roa, I. \& Roa, J. C. Frecuencia de los genes de fusión TEL/AML1 y BCR/ABL en pacientes pediátricos con Leucemia Linfoblástica aguda. Rev. Med. Chil., 134(11):1367-76, 2006.

Artigas, C. G.; Melo, A.; Roa, J. C.; Paez, E.; Vittini, C.; Arriagada, M.; Gonzalez, L.; Pflaumer, E. \& Roa, I. Detection of BCR-ABL gene sequences using RT-PCR in patients with leukemia in the IX region. Chile. Rev. Med. Chil., 130(30):623-6, 2002.

Artigas, C. G.; Melo, A.; Roa, J. C.; Roa I., Quijada I., Vittini C., Roa, I. Cabrera, M.E .; \& Risueño C. Transcriptos de fusión del gen BCR/ ABL en pacientes con leucemia mieloide crónica. Int. J. Morphol., 21(3):205-9, 2003.

Bergamaschi, D.; Samuels, Y.; Jin, B.; Duraisingham, S.; Crook, T. \& Lu, $\mathrm{X}$. ASPP1 and ASPP2: common activators of p53 family members. Mol. Cell Biol., 24(3):1341-50, 2004.

Canalli, A. A.; Yang, H.; Jeha, S.; Hoshino, K.; Sanchez-Gonzalez, B.; Brandt, M.; Pierce, S.; Kantarjian, H.; Issa, J. P. \& Garcia-Manero, G. Aberrant DNA methylation of a cell cycle regulatory pathway composed of P73, P15 and P57KIP2 is a rare event in children with acute lymphocytic leukemia. Leuk. Res., 29(8):881-5, 2005.

Campbell, M. Desarrollo de la Oncología Pediátrica en Chile. Rev. Ped. Elec., 2(2):1-4, 2005,

Corn, P. G.; Kuerbitz, S. J.; van Noesel, M. M.; Esteller, M.; Compitello, N.; Baylin, S. B. \& Herman, J. G. Transcriptional silencing of the p73 gene in acute lymphoblastic leukemia and Burkitt's lymphoma is associated with 5' CpG island methylation. Cancer Res., 59(14):33526,1999

Galm, O.; Herman, J. G. \& Baylin, S. B. The fundamental role of epigenetics in hematopoietic malignancies. Blood Rev., 20(1):1-13, 2006.

Fu, J. F.; Liang, D. C.; Yang, C. P.; Hsu, J. J. \& Shih, L. Y. Molecular analysis of $\mathrm{t}(\mathrm{X} ; 11)(\mathrm{q} 24 ; \mathrm{q} 23)$ in an infant with AML-M4. Genes Chromosomes Cancer, 38(3):253-9, 2003.

Furukawa, Y.; Sutheesophon, K.; Wada, T.; Nishimura, M.; Saito, Y. \& Ishii, $\mathrm{H}$. Methylation silencing of the Apaf-1 gene in acute leukemia. Mol. Cancer Res., 3(6):325-34, 2005.

Herman, J. G.; Graff, J. R.; Myöhänen, S.; Nelkin, B. D. \& Baylin, S. B. Methylation-specific PCR: a novel PCR assay for methylation status of CpG islands. Proc. Natl. Acad. Sci. U S A, 93(18):9821-6, 1996.

Jia, L.; Srinivasula, S. M.; Liu, F. T.; Newland, A. C.; Fernandes-Alnemri, T.; Alnemri, E. S. \& Kelsey, S. M. Apaf-1 protein deficiency confers resistance to cytochrome c-dependent apoptosis in human leukemic cells. Blood, 98(2):414-21, 2001.

Liu, Z. J.; Lu, X. \& Zhong, S. ASPP--Apoptotic specific regulator of p53. Biochim. Biophys Acta, 1756(1):77-80, 2005.

Melki, J. R. \& Clark, S. J. DNA methylation changes in leukaemia. Semin. Cancer Biol., 12(5):347-57, 2002.

Pluta, A.; Nyman, U.; Joseph, B.; Robak, T.; Zhivotovsky, B. \& Smolewski, P. The role of p73 in hematological malignancies. Leukemia, 20(5):75766, 2006.
Pui, C. H. Leucemia linfoblástica aguda. Williams Hematology. $6^{\mathrm{a}}$ ed. Madrid, Marbán Libros, 2005

Pui, C. H.; Robison, L. L. \& Look, A. T. Acute lymphoblastic leukaemia. Lancet, 371(9617):1030-43, 2008.

Reyes S.; Brebi, P.; Ili, C.; Muñoz, S.; Melo, A. \& Guerrero, R. Perfil de Metilación de Genes Supresores de Tumores como Factor Pronóstico en Pacientes con Leucemia Mieloide Aguda. Int. J. Morphol., 29(1):151-7, 2011.

Roman-Gomez, J.; Jimenez-Velasco, A.; Castillejo, J.; Agirre, X., Barrios, M.; Navarro, G.; Molina, F.; Maria J. Calasanz, M.; Prosper, F.; Heiniger, A. \& Torres, A. Promoter hypermethylation of cancer-related genes: a strong independent prognostic factor in acute lymphoblastic leukemia. Blood, 104(8):2492-8, 2004.

Roman-Gomez, J.; Jimenez-Velasco, A.; Agirre, X.; Prosper, F.; Heiniger, A. \& Torres, A. Lack of $\mathrm{CpG}$ island methylator phenotype defines a clinical subtype of T-cell acute lymphoblastic leukemia associated with good prognosis. J. Clin. Oncol., 23(28):7043-9, 2005.

Stam, R. W.; den Boer, M. L.; Passier, M. M. C. J.; Janka-Schaub, G. E.; Sallan, S. E.; Armstrong, S. A. \& Pieters, R. Silencing of the tumor suppressor gene FHITis highly characteristic for MLL gene rearranged infant acute lymphoblastic leukemia. Leukemia, 20(2):264-71, 2006.

Vilas-Zornoza, A.; Agirre, X.; Martin-Palanco, V.; Martin-Subero, J. I.; San Jose-Eneriz, E.; Garate, L.; Alvarez, S.; Miranda, E.; Rodriguez-Otero, P.; Rifon, J.; Torres, A.; Calasanz, M. J.; Cruz Cigudosa, J.; RomanGomez, J. \& Prosper, F. Frequent and simultaneous epigenetic inactivation of TP53 pathway genes in acute lymphoblastic leucemia. PLoS One, 6(2):e17012, 2011

Yang, Y.; Takeuchi, S.; Hofmann, W. K.; Ikezoe, T.; van Dongen, J. J.; Szczepanski, T.; Bartram, C. R.; Yoshino N.; Taguchi, H. \& Koeffler, H. P. Aberrant methylation in promoter-associated $\mathrm{CpG}$ islands of multiple genes in acute lymphoblastic leukemia. Leuk. Res., 30(1):98102,2006

Zheng, S.; Ma, X.; Zhang, L.; Gunn, L.; Smith, M. T.; Wiemels, J. L.; Leung, K.; Buffler, P. A. \& Wiencke, J. K. Hypermethylation of the 5' $\mathrm{CpG}$ island of the FHIT gene is associated with hyperdiploid and translocation-negative subtypes of pediatric leukemia. Cancer Res., 64(6):2000-6, 2004.

\author{
Dirección para Correspondencia \\ Juan Carlos Roa \\ Laboratorio de Patología Molecular \\ Centro de Excelencia en Estudios Genéticos e Inmunológicos \\ (CEGIN) \\ Facultad de Medicina \\ Universidad de La Frontera \\ Manuel Montt 112 of 211 \\ Temuco - CHILE
}

Email: juan.roa@ufrontera.cl

Recibido : 21-06-2013 Aceptado: 29-06-2013 